\title{
MODIFIED OPTIMIZATION WATER INDEX (MOWI) FOR LANDSAT-8 OLI/TIRS
}

\author{
M. Moradi ${ }^{\text {a*}}$, M. Sahebi ${ }^{\text {b }}$, M. Shokri ${ }^{\mathrm{c}}$ \\ ${ }^{\text {a }}$ MSc degree of Photogrammetry, K.N.Toosi University of Technology, Mirdamad, Tehran, Iran - mm136988@yahoo.com \\ ${ }^{\mathrm{b}}$ Head of Remote Sensing research center, K.N.Toosi University of Technology, Mirdamad, Tehran, Iran - sahebi@kntu.ac.ir \\ ${ }^{c}$ MSc degree of Remote Sensing, K.N.Toosi University of Technology, Mirdamad, Tehran, Iran - m.shokri70@ gmail.com
}

KEY WORDS: Water index, optimization, Landsat 8, MOWI, Particle swarm

\begin{abstract}
:
Water is one of the most important resources that essential need for human life. Due to population growth and increasing need of human to water, proper management of water resources will be one of the serious challenges of next decades. Remote sensing data is the best way to the management of water resources due time and cost effectiveness over a greater range of temporal and spatial scales. Between many kinds of satellite data, from SAR to optic or from high resolution to low resolution, Landsat imagery is more interesting data for water detection and management of earth surface water. Landsat8 OLI/TIRS is the newest version of Landsat satellite series. In this paper, we investigated the full spectral potential of Landsat8 for water detection. It is developed many kinds of methods for this purpose that index based methods have some advantages than other methods. Pervious indices just use a limited number of spectral band. In this paper, Modified Optimization Water Index (MOWI) defined by consideration of a linear combination of bands that each coefficient of bands calculated by particle swarm algorithm. The result shows that modified optimization water index (MOWI) has a proper performance on different condition like cloud, cloud shadow and mountain shadow.
\end{abstract}

\section{INTRODUCTION}

Water is one of most important earth resources that about 71 percent of the Earth's surface is covered by water (Williams 2014). Rapid population increase and unplanned urbanization leading to decrease of water bodies. Monitoring and proper management of water resources such rivers, lakes as natural reservoirs and dams as a man-made reservoir are essential to human health, society, agriculture, global carbon cycle and climate variations (Brezonik, Menken et al. 2005, Prasad, Rajan et al. 2009). Remote sensing data has been widely used for water detection in last 3 decades rather than ground-based methods with the advent and development of remote sensing sensors and methods due to a time and cost effectiveness over a greater range of temporal and spatial scales (Wang, Ruan et al. 2011). Therefore, water detection is an interesting field of experts and researchers of remote sensing and photogrammetry.

Landsat imagery is one of the most wildly used remote sensing data that applied in most previous studies for water body detection or water change detection. The Landsat series of satellites have many sensor and generation. Multispectral Scanner System (MSS) for landsat-1 to landsat-3 (1972-1983), Thematic Mapper (TM) for landsat-4 to landsat-5 (1982-2012) and Enhanced Thematic Mapper Plus (ETM+) for landsat-7 (1999-now) have been used for many application especially water index and water body detection (McFeeters 1996, Xu 2006). The newest generation of Landsat series of satellites is landsat-8 that lunched on 2013. Operational Land Imager (OLI) sensor of landsat- 8 has 12 -bit pixel value rather than the 8 -bit pixel value of ETM+ images that lead to higher quality and improve three times better signal to noise ratio (SNR) than ETM+ (Irons, Dwyer et al. 2012).

There are many kinds of algorithm have been adopted for water detection especially on Landsat data that categorized into four main groups: 1- classification and pattern recognition methods that include supervised (Tulbure and Broich 2013) and unsupervised methods (Ko, Kim et al. 2015), 2- spectral unmixing (Sethre, Rundquist et al. 2005), 3- single-band thresholding (Klein, Dietz et al. 2014), 4- the spectral water index (Ji, Zhang et al. 2009). Classification methods have a better performance than thresholding methods. If images consist of complex topologies such as mountain shadows, roads, and urban areas, high false classification rate may be achieved in water body detection process (Ko, Kim et al. 2015). Also, classification methods are highly dependent on human and have some difficulty (Ouma and Tateishi. 2006). Index-based methods can detect water body more accurately, quickly and easily than classification methods and does not need any prior knowledge (Li, Du et al. 2013), especially on low-resolution images and single-class (water) study.

There are many kinds of water indices in past studies. One of popular water index is the normalized difference water index (NDWI) (McFeeters 1996). The other one is the modified NDWI (Xu 2006) that introduced to overcome the inseparability of built up areas in NDWI. Automated water extraction index (AWEI) introduced for better result achieving in an area by shadow and dark surface on Landsat TM. AWEInsh and AWEIsh are used for an area by urban background and area by shadow respectively (Feyisa, Meilby et

* Corresponding author 
al. 2014).Water Ratio Index (WRI) is another widely used water index (Shen and Li 2010).

Amare Sisay (2016), used NDWI for MSS image data due lacks mid-infrared band (MIR) and AWEI for TM, ETM+, and OLI_TIRS for change detection of central rift valley region of Ethiopia (Sisay 2016). DU et al. (2014), tested three NDWI models include NDWIo5,3, NDWIo6,3, NDWIo7,3 based on reflectance value that result show the better accuracy of NDWIo6,3 than two other models (Du, Li et al. 2014). Liu et al. (2016), indicated that $\mathrm{NDWI}_{3,5}$ and $\mathrm{NDWI}_{5,6}$ have better performance by reflectance images whereas NDWI3,6 has better performance by DN value images (Liu, Yao et al. 2016). Blackmore (2016), showed the effectiveness of NDWI and MNDWI for open water and surface moisture detection. Also, results of this study indicated that NDWI is more sensitive to an area with vegetation (Blackmore 2016). Xie et al. (2016), studied about clear water, turbid water, and eutrophic water. The results indicated that AWEIsh, NDWI 4,7 and NDWI 3,7 with accuracies of $98.55 \%, 95.50 \%$, and $96.61 \%$ have the highest accuracy to clear water, turbid water, and eutrophic water, respectively (Xie, Luo et al. 2016).

It should be noted that all of the above mentioned spectral indices only use a limited number of bands that may lead to the poor result for pixels that contaminated by ice, snow or cloud. In this paper, a modified optimization water index (MOWI) is proposed to use the full spectral potential of landsat- 8 OLI/TIRS as the newest generation of Landsat series of satellites in water detection and reduce shadow effects, cloud effects and other disturbing factors. The proposed method can be considered as classification method or index-base method that we have an index-based view in this paper.

\section{WATER INDICES}

In this section, an overview of the water indices is presented. By considering high reflectance of green band and low reflectance of near infrared band for water, normalized difference water index (NDWI) defined as bellow (McFeeters 1996):

$$
N D W I=\frac{b_{\text {green }}-b_{\text {nir }}}{b_{\text {green }}+b_{\text {nir }}}
$$

Modified normalized difference water index (MNDWI) is achieved with replacing infrared by shortwave infrared that its wavelength is [1.57-1.65] micrometers (SWIR1). MNDWI defined as bellow (Ji, Geng et al. 2015):

$$
M N D W I=\frac{b_{\text {green }}-b_{\text {swir } 1}}{b_{\text {green }}+b_{\text {swir } 1}}
$$

Automated water extraction index (AWEI) use four bands unlike two bands of NDWI and MNDWI. This index defined as bellow (Ji, Geng et al. 2015):

$$
\begin{aligned}
& A W E I_{\text {nsh }}=4 \times\left(b_{\text {green }}-b_{\text {swir } 1}\right)-\left(0.25 \times b_{\text {nir }}+2.75 \times b_{\text {swir } 2}\right) \\
& A W E I_{\text {sh }}=b_{\text {blue }}+0.25 \times b_{\text {green }}-1.5 \times\left(b_{\text {nir }}+b_{\text {swir } 1}\right)-0.25 \times b_{\text {swir } 2}
\end{aligned}
$$

Water ratio index is another water index that defined as bellow (Rokni, Ahmad et al. 2014, Sisay 2016):

$$
W R I=\frac{b_{\text {green }}+b_{\text {red }}}{b_{\text {nir }}+b_{\text {mir }}}
$$

\section{THE PROPOSED METHOD}

All of the previous indices calculated by the commentary of spectral curvature but in this paper, another approach has been adopted that use combination of bands for water detection under a linear combination of bands. The coefficient of each band is determined by the optimization algorithm. This linear combination defined as bellow:

$$
\text { MOWI }=\sum_{i=1}^{N} a_{i} \times b_{i}
$$

$N$ : number of bands

$a_{i}$ : coefficient of band i, $a_{i} \in[-10,10]$

$b_{i}:$ band i

Proposed method can be adopted at two strategies:

1- Classification-based: in this strategy, coefficients calculated by some test and some terrain pixel. Then water body or surface can be detected by applying these coefficients. These coefficients are proper just for this image.

2- Index-based: in this strategy, coefficients calculated on one image by test and obtained water index. Then we can apply this index to other images.

In this study, the index-based strategy has been used for water detection that used all bands instead of using a limited number of bands. The flowchart of the proposed method is presented in Figure 1.

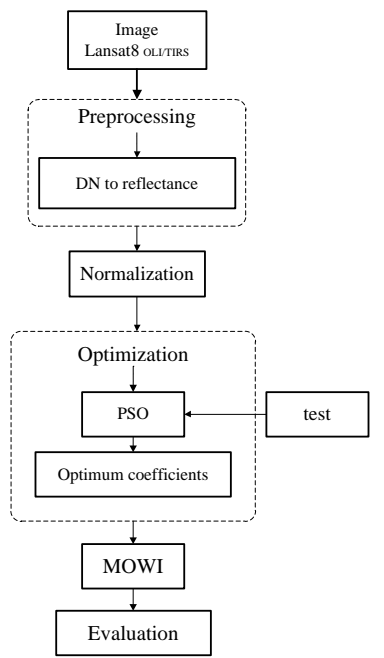

Figure 1. Schema of the proposed method

\subsection{Study area and Data source}

Landsat- 8 is the newest generation of Landsat series of satellites that is the most interesting source for water detection studies. In order to reach the final aim of this study, four Landsat 8 OLI/TIRS images were collected from the US Geological Survey (USGS) Global Visualization Viewer (collection 1 level-1). All of these four case studies are in Iran and includes Zarivar Lake, Kazemi Dam, Gotvand Dam and Karun-1 Dam. These images have a different condition like cloud and shadow that are disturbing factor for water detection. In this paper, we wanted to use all potential of spectral space for water index definition. So, 10 bands of landsat- 8 had been used to determined water index. Table 1 presents the specifications of Landsat 8 OLI/TIRS images (Rokni, Ahmad et al. 2014, Sisay 2016). 
Table 1. Landsat-8 bands information

\begin{tabular}{|c|c|c|}
\hline Wavelength $(\mu \mathrm{m})$ & Band & This paper \\
\hline Band 1: $0.43-0.45$ & Coastal aerosol & b1 \\
\hline Band 2: $0.45-0.51$ & Blue & b2 \\
\hline Band 3: $0.53-0.59$ & Green & b3 \\
\hline Band 4: $0.64-0.67$ & Red & b4 \\
\hline Band 5: 0.85 - 0.88 & Near IR & b5 \\
\hline Band 6: $1.57-1.65$ & SWIR 1 & b6 \\
\hline Band 7: 2.11 - 2.29 & SWIR 2 (MIR) & b7 \\
\hline Band 8: $0.50-0.68$ & Panchromatic & - \\
\hline Band 9: $1.36-1.38$ & Cirrus & b10 \\
\hline Band 10:10.60 - 11.19 & $\begin{array}{c}\text { Thermal Infrared } \\
\text { (TIRS) } 1\end{array}$ & b8 \\
\hline Band 11: $11.50-12.51$ & $\begin{array}{c}\text { Thermal Infrared } \\
\text { (TIRS) 2 }\end{array}$ & b9 \\
\hline
\end{tabular}

\subsection{Preprocessing}

Preprocessing is one of the most important steps for each photogrammetry and remote sensing analysis. In this paper, the original DN values had to be converted into radiance and then into reflectance.

\subsection{Normalization}

Reflectance values normalized between $[0,1]$ by equation 6 .

$$
N b_{i}=\frac{b_{i}-\min \left(\min \left(b_{i}\right)\right)}{\max \left(\max \left(b_{i}\right)\right)-\min \left(\min \left(b_{i}\right)\right)}
$$

\subsection{Optimization}

Particle swarm optimization (PSO) is a population based metaheuristic algorithm that has a simple programming, high run speed and high convergence rate that proposed in 1995 by Kennedy and Eberhart (Eberhart and Kennedy 1995). Here,
PSO is used to find optimum coefficients for each band for have a proper water index. The overall accuracy is considered as objective function and variables (coefficients) domain is considered in $[-10,10]$. The coefficients of the index (modified optimization water index (MOWI)) are calculated on Karun-1 Dam due to having water, shadow, and cloud.

\subsection{Evaluation}

After calculated coefficients and modified optimization water index on Karun-1 Dam, MOWI evaluated on three other case studies by the recall, Precision (P), f-score, overall accuracy (OA) and kappa coefficient (K).

\section{EXPERIMENTAL RESULTS AND DISCUSSIONS}

Coefficients of each band that calculated by particle swarm optimization are as bellow.

Table 2. Optimized coefficients of each band

\begin{tabular}{|l|l|}
\hline \multicolumn{1}{|c|}{ Band } & \multicolumn{1}{c|}{ Coefficient } \\
\hline b1: Coastal aerosol & -0.969616734045172 \\
\hline b2: Blue & 2.19807138881102 \\
\hline b3: Green & 5.85814134568662 \\
\hline b4: Red & 0.370296018291466 \\
\hline b5: Near IR & -8.72362757074720 \\
\hline b6: SWIR 1 & -4.33503214968681 \\
\hline b7: SWIR2 & 2.64552671963812 \\
\hline b8: Thermal Infrared (TIRS) 1 & 1.51971484483010 \\
\hline b9: Thermal Infrared (TIRS) 2 & 0.593968608786066 \\
\hline b10: Cirrus & -0.906978774853697 \\
\hline
\end{tabular}

Table 3 show the statistical results of MOWI and other indices for water detection. Also, table 4 show the maps of water indices on each case study.

Table 3. Statistical results of indices

\begin{tabular}{|c|c|c|c|c|c|c|c|c|}
\hline \multirow{2}{*}{ Case study } & \multirow{2}{*}{ indices } & \multicolumn{2}{|c|}{ Recall } & \multicolumn{2}{|c|}{$\mathrm{P}$} & \multirow{2}{*}{ f-score } & \multirow{2}{*}{ OA } & \multirow{2}{*}{$\mathrm{K}$} \\
\hline & & No water & water & No water & water & & & \\
\hline \multirow{5}{*}{ Karun-1 Dam } & MOWI & 99.4186 & 100 & 100 & 99.9207 & 99.7085 & 99.9301 & 0.9967 \\
\hline & NDWI & 89.4057 & 99.9603 & 99.6759 & 98.5733 & 94.2619 & 98.6921 & 0.9353 \\
\hline & MNDWI & 98.1116 & 95.3407 & 72.0530 & 99.7581 & 83.0870 & 95.6430 & 0.8065 \\
\hline & AWEIsh & 98.9664 & 99.9956 & 99.9674 & 99.8590 & 99.4644 & 99.8719 & 0.9939 \\
\hline & WRI & 86.1575 & 94.8535 & 67.2103 & 98.2446 & 75.5135 & 93.9050 & 0.7209 \\
\hline \multirow{5}{*}{ Gotvand Dam } & MOWI & 99.9822 & 99.9966 & 99.9941 & 99.9898 & 99.9881 & 99.9914 & 0.9998 \\
\hline & NDWI & 99.9881 & 99.9898 & 99.9822 & 99.9932 & 99.9852 & 99.9892 & 0.9998 \\
\hline & MNDWI & 99.9704 & 100 & 100 & 99.9830 & 99.9852 & 99.9892 & 0.9998 \\
\hline & AWEIsh & 100 & 99.9966 & 99.9940 & 100 & 99.9970 & 99.9978 & 0.9999 \\
\hline & WRI & 99.9466 & 99.9966 & 99.9941 & 99.9695 & 99.9703 & 99.9784 & 0.9995 \\
\hline \multirow{5}{*}{ Kazemi Dam } & MOWI & 99.9854 & 100 & 100 & 99.9872 & 99.9927 & 99.9932 & 0.9999 \\
\hline & NDWI & 99.9854 & 100 & 100 & 99.9872 & 99.9927 & 99.9932 & 0.9999 \\
\hline & MNDWI & 100 & 100 & 100 & 100 & 100 & 100 & 1 \\
\hline & AWEIsh & 99.9709 & 99.9872 & 99.9854 & 99.9743 & 99.9781 & 99.9795 & 0.9996 \\
\hline & WRI & 100 & 100 & 100 & 100 & 100 & 100 & 1 \\
\hline \multirow{5}{*}{ Zarivar Lake } & MOWI & 93.1862 & 99.9658 & 99.8971 & 97.6314 & 96.4250 & 98.1862 & 0.9521 \\
\hline & NDWI & 83.1574 & 100 & 100 & 94.3442 & 90.8043 & 95.5788 & 0.8793 \\
\hline & MNDWI & 83.2054 & 99.9317 & 99.7699 & 94.3557 & 90.7378 & 95.5410 & 0.8783 \\
\hline & AWEIsh & 92.5624 & 100 & 100 & 97.4210 & 96.1376 & 98.0476 & 0.9483 \\
\hline & WRI & 81.8618 & 100 & 100 & 93.9355 & 90.0264 & 95.2387 & 0.8694 \\
\hline
\end{tabular}


Table 4. Result of each index on each case study

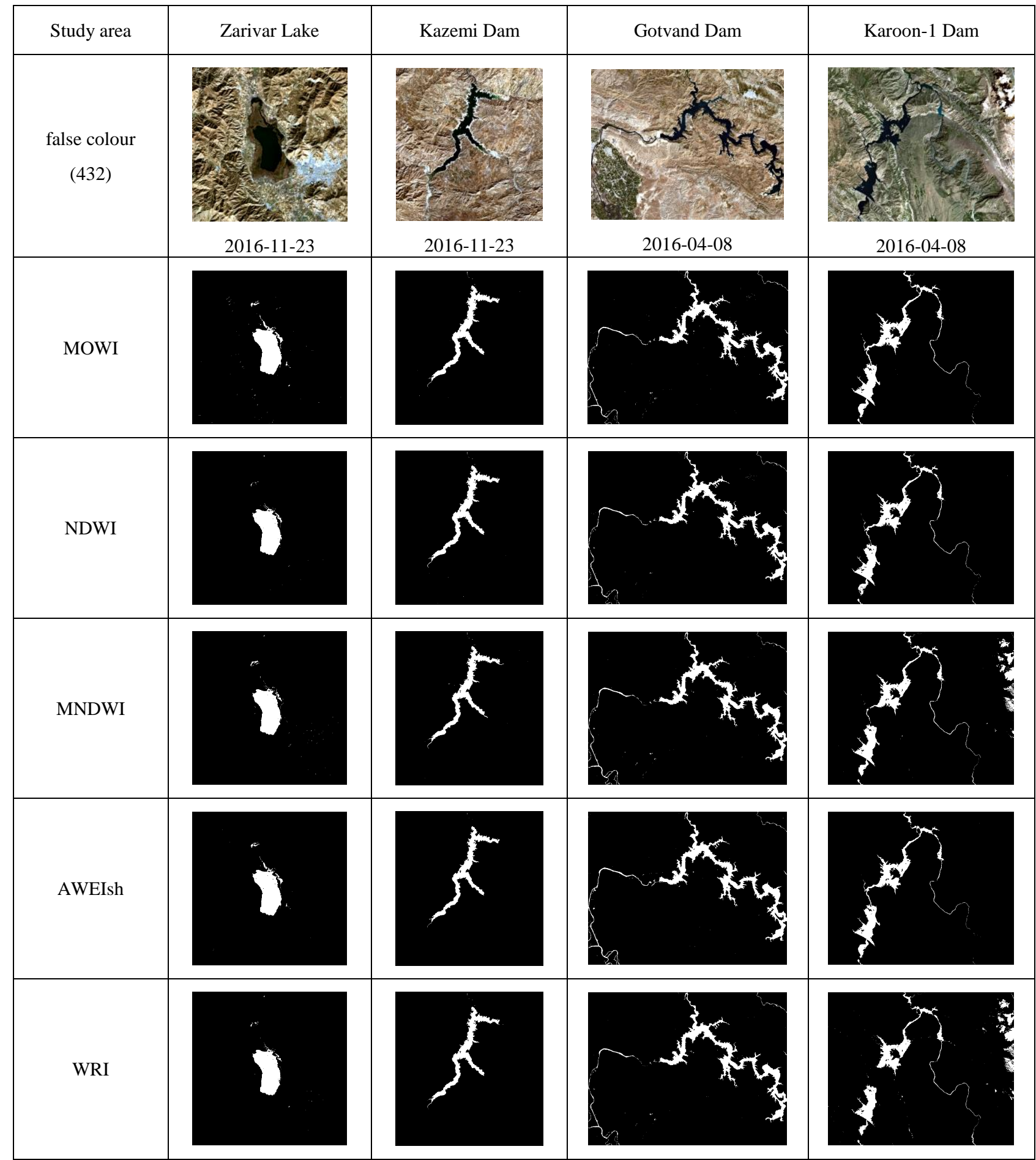

In the case study of Karun-1 Dam, MOWI has the best performance by $99.7085,99.9301$ and 0.9967 for f-score, overall accuracy, and kappa coefficient respectively. The result of this case study shows the problem of MNDWI and WRI by cloud and its shadow. Also, AWEIsh has a little problem for narrow water detection especially at down-right and NDWI has a little weak result in water detection at down-left.

In the case study of Gotvand Dam, AWEIsh has the best performance by $99.9970,99.9978$ and 0.9999 for f-score, overall accuracy, and kappa coefficient respectively. However, this index has less noise than other indices but has a little problem for narrow water detection at middle-top and middleleft. After AWEIsh, MOWI has the best performance in this case study by $99.9881,99.9914$ and 0.9998 for f-score, overall accuracy, and kappa coefficient respectively that has a little difference by AWEIsh.

In the case study of Kazemi Dam, MNDWI and WRI have the best result but MOWI and NDWI performance have the little 
difference by MNDWI and WRI. Also, AWEIsh has the lowest accuracy.

Results of Zarivar Lake show the better performance of MOWI by $96.4250,98.1862$ and 0.9521 for f-score, overall accuracy, and kappa coefficient respectively. Also, WRI has the poor result on this case study.

Results of four subsets show that MNDWI and WRI have the problem by cloud and its shadow, and AEWI has a little problem for narrow water detection. MOWI has the best result in two case study and has the little difference by best results of two other case study result. Totally, MOWI uses all potential of landsat- 8 images for water detection that has the desirable results on the different case study by different condition such as cloud, its shadow and mountain shadow.

\section{CONCLUSION}

Water is one of the important resources that should be managed properly for needs of human life in future. One of best tools for water resource management is remote sensing data and techniques. Also, water detection is one of interest subjects of photogrammetry and remote sensing researcher. Between many kinds of satellite data, Landsat imagery is the more interesting data for water detection especially Landsat8 OLI/TIRS that is the newest version of Landsat satellite series. In this paper, we investigated the full spectral potential of Landsat 8 to calculate the water index by consideration of the linear combination of bands. Particle swarm optimization had been sued for calculation of each band coefficient. The result showed that modified optimization water index (MOWI) has a proper performance on different condition like cloud, cloud shadow and mountain shadow.

\section{ACKNOWLEDGMENT}

The author's would like to thank US Geological Survey (USGS) for data provision.

\section{REFERENCES}

Blackmore, D. S. (2016). "Use of Water Indices Derived from Landsat OLI Imagery and GIS to Estimate the Hydrologic Connectivity of Wetlands in the Tualatin River National Wildlife Refuge".

Brezonik, P., K. D. Menken and M. Bauer (2005). "Landsatbased remote sensing of lake water quality characteristics, including chlorophyll and colored dissolved organic matter (CDOM)." Lake and Reservoir Management 21(4): 373-382.

Du, Z., W. Li, D. Zhou, L. Tian, F. Ling, H. Wang, Y. Gui and B. Sun (2014). "Analysis of Landsat-8 OLI imagery for land surface water mapping." Remote sensing letters 5(7): 672-681.

Eberhart, R. and J. Kennedy (1995). A new optimizer using particle swarm theory. Micro Machine and Human Science, 1995. MHS'95., Proceedings of the Sixth International Symposium on, IEEE.

Feyisa, G. L., H. Meilby, R. Fensholt and S. R. Proud (2014). "Automated Water Extraction Index: A new technique for surface water mapping using Landsat imagery." Remote Sensing of Environment 140: 23-35.
Irons, J. R., J. L. Dwyer and J. A. Barsi (2012). "The next Landsat satellite: The Landsat data continuity mission." Remote Sensing of Environment 122: 11-21.

Ji, L., X. Geng, K. Sun, Y. Zhao and P. Gong (2015). "Target detection method for water mapping using landsat 8 oli/tirs imagery." Water 7(2): 794-817.

Ji, L., L. Zhang and B. Wylie (2009). "Analysis of dynamic thresholds for the normalized difference water index." Photogrammetric Engineering \& Remote Sensing 75(11): 13071317.

Klein, I., A. J. Dietz, U. Gessner, A. Galayeva, A. Myrzakhmetov and C. Kuenzer (2014). "Evaluation of seasonal water body extents in Central Asia over the past 27 years derived from medium-resolution remote sensing data." International Journal of Applied Earth Observation and Geoinformation 26: 335-349.

Ko, B. C., H. H. Kim and J. Y. Nam (2015). "Classification of potential water bodies using Landsat 8 OLI and a combination of two boosted random forest classifiers." Sensors 15(6): 13763-13777.

Li, W., Z. Du, F. Ling, D. Zhou, H. Wang, Y. Gui, B. Sun and X. Zhang (2013). "A comparison of land surface water mapping using the normalized difference water index from TM, ETM+ and ALI." Remote Sensing 5(11): 5530-5549.

Liu, Z., Z. Yao and R. Wang (2016). "Assessing methods of identifying open water bodies using Landsat 8 OLI imagery." Environmental Earth Sciences 75(10): 1-13.

McFeeters, S. K. (1996). "The use of the Normalized Difference Water Index (NDWI) in the delineation of open water features." International journal of remote sensing 17(7): 1425-1432.

Ouma, Y. O. and R. Tateishi (2006). "A water index for rapid mapping of shoreline changes of five East African Rift Valley lakes: an empirical analysis using Landsat TM and ETM+ data." International Journal of Remote Sensing 27(15): 3153-3181.

Prasad ,P. R. C., K. Rajan, V. Bhole and C. Dutt (2009). "Is rapid urbanization leading to loss of water bodies?" Journal of Spatial Science 2(2): 43-52.

Rokni, K., A. Ahmad, A. Selamat and S. Hazini (2014). "Water feature extraction and change detection using multitemporal Landsat imagery." Remote Sensing 6(5): 4173-4189.

Sethre, P. R., B. C. Rundquist and P. E. Todhunter (2005). "Remote detection of prairie pothole ponds in the Devils Lake Basin, North Dakota." GIScience \& Remote Sensing 42(4): 277-296.

Shen, L and C. Li (2010). Water body extraction from Landsat ETM+ imagery using adaboost algorithm. Geoinformatics, 2010 18th International Conference on, IEEE.

Sisay, A. (2016). "Remote Sensing Based Water Surface Extraction and Change Detection in the Central Rift Valley Region of Ethiopia." American Journal of Geographic Information System 5(2): 33-39.

Tulbure, M. G. and M. Broich (2013). "Spatiotemporal dynamic of surface water bodies using Landsat time-series data from 1999 to 2011." ISPRS Journal of Photogrammetry and Remote Sensing 79: 44-52. 
Wang, Y., R. Ruan, Y. She and M. Yan (2011). "Extraction of water information based on RADARSAT SAR and Landsat ETM+." Procedia Environmental Sciences 10: 2301-2306.

Williams, M. (2014). "What Percent of Earth is Water." Universe Today. Available at http://www. universetoday. com/65588/what-percent-of-earth-is.

Xie, H., X. Luo, X. Xu, H. Pan and X. Tong (2016). "Evaluation of Landsat 8 OLI imagery for unsupervised inland water extraction." International Journal of Remote Sensing 37(8): 1826-1844.

$\mathrm{Xu}, \mathrm{H}$. (2006). "Modification of normalised difference water index (NDWI) to enhance open water features in remotely sensed imagery." International journal of remote sensing 27(14): 3025-3033. 